\title{
Neutrophil-to-Lymphocyte Ratio Is an Independent Predictor for In-Hospital Mortality in Spontaneous Intracerebral Hemorrhage
}

\author{
Antje Giede-Jeppe ${ }^{a}$ Tobias Bobinger ${ }^{a} \quad$ Stefan T. Gerner ${ }^{a} \quad$ Jochen A. Sembilla \\ Maximilian I. Sprügel ${ }^{a}$ Vanessa D. Beuscher ${ }^{a}$ Hannes Lücking ${ }^{b}$ \\ Philip Hoelter $^{\text {b Joji B. Kuramatsu }}{ }^{\text {a Hagen B. Huttner }}{ }^{\text {a }}$ \\ ${ }^{a}$ Department of Neurology, and b Department of Neuroradiology, University of Erlangen-Nuremberg, Erlangen, \\ Germany
}

\section{Keywords}

Intracerebral hemorrhage · Neutrophil-to-lymphocyte ratio $\cdot$ Inflammation $\cdot$ In-hospital mortality

\begin{abstract}
Background and Purpose: Stroke-associated immunosuppression and inflammation are increasingly recognized as factors that trigger infections and thus, potentially influence the outcome after stroke. Several studies demonstrated that elevated neutrophil-to-lymphocyte ratio (NLR) is a significant predictor of adverse outcomes in patients with ischemic stroke. However, little is known about the impact of NLR on short-term mortality in intracerebral hemorrhage (ICH). Methods: This observational study included 855 consecutive ICH-patients. Patient demographics, clinical, laboratory, and in-hospital measures as well as neuroradiological data were retrieved from institutional databases. Functional 3-monthsoutcome was assessed and categorized as favorable (modified Rankin Scale [mRS] 0-3) and unfavorable (mRS 4-6). We (i) studied the natural course of NLR in ICH, (ii) analyzed parameters associated with NLR on admission (NLROA), and (iii) evaluated the clinical impact of NLR on mortality and functional outcome. Results: The median NLROA of the entire cohort was 4.66 and it remained stable during the entire hospital stay. Patients with NLR $\geq 4.66$ showed significant associations with poorer neurological status (National Institute of
\end{abstract}

Health Stroke Scale [NIHSS] 18 [9-32] vs. 10 [4-21]; $p<0.001)$, larger hematoma volume on admission (17.6 [6.9-47.7] vs. 10.6 [3.8-31.7] $\mathrm{mL} ; p=0.001$ ), and more frequently unfavorable outcome (mRS 4-6 at 3 months: $317 / 427$ [74.2\%] vs. 275/428 [64.3\%]; $p=0.002$ ). Patients with an NLR under the 25th percentile (NLR<2.606) - compared to patients with NLR $>2.606$ - presented with a better clinical status (NIHSS 12 [521 vs. 15 [6-28]; $p=0.005)$, lower hematoma volumes on admission (10.6 [3.6-30.1] vs. $15.1[5.7-42.3] \mathrm{mL} ; p=0.004)$ and showed a better functional outcome (3 months mRS $0-3$ : $82 / 214$ [38.3\%] vs. $185 / 641$ [28.9\%]; $p=0.009$ ). Patients associated with high NLR ( $\geq 8.508=$ above 75th-percentile) showed the worst neurological status on admission (NIHSS 21 [12-32] vs. 12 [5-23]; $p<0.001$ ), larger hematoma volumes (21.0 [8.6-48.8] vs. 12.2 [4.1-34.9] $\mathrm{mL} ; p<0.001)$, and higher proportions of unfavorable functional outcome at 3 months (mRS 4-6: $173 / 214$ vs. 418/641; $p<0.001$ ). Further, NLR was linked to more frequently occurring infectious complications (pneumonia $107 / 214$ vs. $240 / 641 ; p=0.001$, sepsis: $78 / 214$ vs. $116 / 641 ; p<0.001)$, and increased c-reactive-protein levels on admission $\left(p<0.001 ; R^{2}=0.064\right)$. Adjusting for the abovementioned baseline confounders, multivariable logistic analyses revealed independent associations of NLROA with inhospital mortality (OR $0.967,95 \% \mathrm{Cl} 0.939-0.997 ; p=0.029)$. Conclusions: NLR represents an independent parameter associated with increased mortality in ICH patients. Stroke physicians should focus intensely on patients with increased NLR,

\section{KARGER}

(c) 2017 S. Karger AG, Basel

E-Mail karger@karger.com

www.karger.com/ced
Dr. Antje Giede-Jeppe, MD

Department of Neurology

University Hospital Erlangen

Schwabachanlage 6, DE-91054 Erlangen (Germany)

E-Mail Antje.Giede-Jeppe@uk-erlangen.de 
as these patients appear to represent a population at risk for infectious complications and increased short-mortality. Whether these patients with elevated NLR may benefit from a close monitoring and specially designed therapies should be investigated in future studies.

(c) 2017 S. Karger AG, Basel

\section{Introduction}

Inflammation plays an important role in cerebrovascular diseases [1-4], including intracerebral hemorrhage (ICH) [5-7] and is usually monitored using a variety of biochemical and hematological markers [8-12]. Neutrophil-to-lymphocyte ratio (NLR), calculated by the absolute neutrophil count divided by the absolute lymphocyte count, is increasingly recognized as a readily available and inexpensive biomarker for systemic inflammation [13]. NLR reflects the balance between innate (neutrophile granulocytes) and adaptive (lymphocytes) immune responses as neutrophil elevation and lymphocyte depletion indicate physiological stress $[14,15]$.

Recently, in some ICH-studies, NLR has been associated with clinical endpoints [2, 12, 16-19]. However, in ICH patients, little is known about the natural course of systemic inflammation during hospital stay and whether NLR is associated with short-term mortality. This study for the first time investigated (i) the course of NLR, (ii) parameters associated with NLR, and (iii) the clinical impact of NLR on mortality and functional outcome after ICH.

\section{Methods}

\section{Patient Selection}

We analyzed all consecutive patients with spontaneous ICH admitted to the Department of Neurology, University Hospital Erlangen, Germany, between 2006 and $2014(n=960)$. By definition, we excluded secondary ICH etiologies, that is, ICH related to trauma, tumor, arteriovenous malformation, central venous thrombosis, subarachnoid hemorrhage or thrombolysis, as previously defined [20]. We did not include patients receiving permanent immunomodulatory treatments prior to admission, for example, consisting of corticosteroids, methotrexate, other cytostatic drugs and biologicals (monoclonal antibodies) and excluded all individuals with hematological, autoimmune, or infectious diseases. As 105 patients had no follow-up data, or refused consent, 855 patients participated in the final analysis.

\section{Parameter Acquisition}

As described previously [21], we retrieved data of all patients from our institutional prospective database. We reviewed data for demographics, prior medical history, imaging, and in-hospital pa- rameters (Glasgow Coma Scale [GCS], National Institute of Health Stroke Scale [NIHSS], ICH-score, blood pressure, mechanical ventilation, length of stay, external ventricular drainage, diagnosis of pneumonia, urinary tract infection and sepsis, as defined elsewhere) [22-25].

Laboratory parameters were retrieved from our institutional database. We investigated NLR that was obtained immediately upon admission (NLROA) and subsequently during hospital stay in the morning (NLR days 1, 2, 3, 5, 7, 10, and 14). However, in cases of infections and need of frequent blood controls, we did not consider this additional blood work taken during other times of the day to avoid confounding. NLR was calculated by dividing the absolute neutrophil count by the absolute lymphocyte count [5, 13 ] and average values for healthy controls $(\mathrm{NLR}=2.24)$ were defined according to representative samples [26]. We chose to use a median split and 25th/75th percentile quartiles to categorize our ICH-patients.

We assessed patients' characteristics, for example, history of stroke, cardiovascular comorbidity, nicotine or alcohol abuse, using standardized mailed questionnaires. Semi-quantitative phone interviews were conducted - performed by physicians trained and certified for data collection on disability and quality of life - with patients or their closest relatives if the questionnaire was not returned within 2-4 weeks [21]. We contacted primary care physicians only in cases of insufficient data retrieval.

\section{Outcome Measures}

We obtained data on mortality and functional outcome as described above using the modified Rankin Scale (mRS) [27]. Functional outcome was evaluated using the mRS on day 90 after $\mathrm{ICH}$ onset. Favorable outcome was defined as mRS $0-3$ and unfavorable outcome as mRS 4-6.

\section{Imaging}

As described previously [21], we diagnosed ICH by CT (SOMATOM Volume Zoom or SOMATOM Definition AS+, Siemens Healthcare GmbH, Forchheim/Germany) or MRI (Siemens Magnetom Aera, 1.5T, Siemens Healthcare GmbH, Erlangen/ Germany). Two neuroradiologists (H.L. and P.H.) blinded to clinical data reviewed the scans independently and in cases of discrepancies made a second consensus analysis. We calculated $\mathrm{ICH}$ volume according to the $\mathrm{ABC} / 2$-formula and $\mathrm{ABC} / 3$-formula in irregularly shaped ICH $[28,29]$. An increase in volume $>33 \%$ upon follow-up was determined as hematoma enlargement [30]. Using the Graeb score summation, we scored the amount of intraventricular hematoma (IVH) [31].

\section{Statistical Analysis}

We used the statistical software package SPSS 20.0 (IBM Analytics; www.spss etc.). The significance level was set at $\alpha=0.05$ twosided. We used the Kolmogorov-Smirnov test to determine the distribution of data. Data compared with normal distribution using the Student $t$ test are presented as mean \pm SD. Continuous variables without normal distribution were analyzed using the Mann-Whitney U test and obtained as median (50th) values and interquartile ranges (25th/75th). Categorical variables were presented as frequency and percentage. We used the Pearson chi square and the Fisher's exact tests to compare frequency distributions of categorized variables between patients with median split and 25 th/75th-percentile NLROA. To identify parameters inde- 


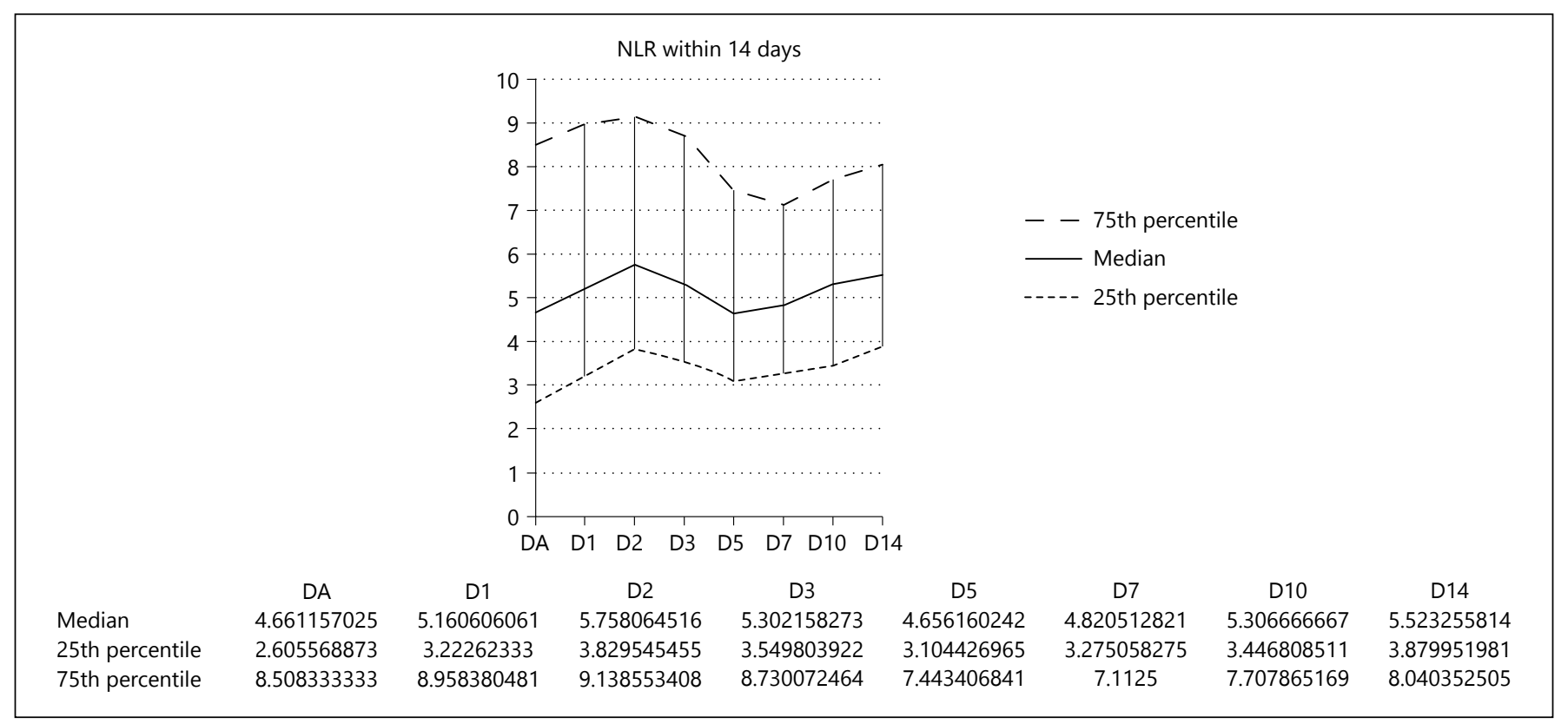

Fig. 1. Course of neutrophile-to-lymphocyte ratio within 14 days after admission.

pendently associated with outcome, we developed step-wise forward inclusion multivariate logistic regression models including parameters showing a statistical trend $(p<0.1)$ in univariate testing.

\section{Results}

\section{NLR over Time - Prevalence, Related Factors,} and Outcome

The median NLR of the entire cohort was 4.66 on admission; the nadir occurred at day $5(\mathrm{NLR}=4.65$; Fig. 1$)$. Patients with an NLR $\geq 4.66$, compared to patients with an NLR $<4.66$ on admission, presented with higher NIHSS (18 [9-32] vs. 10 [4-21]; $p<0.001)$, larger hematoma volumes on admission (17.6 [6.9-47.7] vs. 10.6 [3.8-31.7] $\mathrm{mL} ; p<0.001)$ and more frequent IVH $(258 / 427$ [60.4\%] vs. $167 / 428$ [39.0\%]; $p<0.001)$, more frequently developing pneumonia (195/427 [45.7\%] vs. $150 / 428$ [35.1\%]; $p=0.002)$ and sepsis (117/427 [27.4\%] vs. $77 / 428$ [18.0\%]; $p=0.001)$, necessity of ventilation $(238 / 427$ [55.7\%] vs. $150 / 428$ [35.1\%]; $p<0.001)$, and increased rates of external ventricular drain placement (159/428 [37.2\%] vs. 100/427 [23.4\%]; $p<0.001$; Table 1). Both mortality (178/427 [41.7\%] vs. $127 / 428$ [29.7\%]; $p<$ 0.001 ) and the proportion of patients with unfavorable functional outcome at 3 months (317/427 [74.2\%] vs. $275 / 428[64.3 \%] ; p=0.002)$ were significantly higher in patients with NLR $\geq 4.66$ (Fig. 2).
Multivariable logistic regression models were performed to adjust for baseline confounders and to study possible independent effects of NLROA. NLROA was significantly associated with in-hospital mortality (NLROA: OR 0.967 [95\% CI 0.939-0.997]; $p=0.029$; online suppl. Table 1; for all online suppl. material, see www.karger. com/doi/10.1159/000468996) and showed a statistical trend on 3-month mortality (NLROA: OR 0.974 [95\% CI $0.945-1.004] ; p=0.087$; online suppl. Table 2$)$. In contrast to published results [6], we did not identify NLR as an independent variable for unfavorable functional outcome at 3 months (NLROA: OR 0.983 [95\% CI 0.939$1.029] ; p=0.453$; online suppl. Table 3 ). NLROA showed a statistical trend to be independently associated with development of a sepsis (NLROA: OR 1.028 [95\% CI 0.9981.059]; $p<0.071$; online suppl. Table 4) and there were significant associations of NLROA and C-reactive protein (CRP) concentrations $(\mathrm{mg} / \mathrm{L})$ on admission $(p<$ 0.001, $R^{2}=0.064$; Fig. 3).

\section{Clinical Significance of Increased and Decreased NLR}

Given an average definition $(\mathrm{NLR}=2.24)$ according to a nationally representative sample for healthy controls [26], we compared patients with an NLR under the 25thpercentile (NLR $<2.606)$ to those with an NLR $\geq 2.606$, and patients with NLR above the 75th-percentile (NLR $\geq 8.508$ ) to patients with NLR $<8.508$. Out of 855 patients, 214 had an NLR $<2.606$ (Table 2). These patients present- 
Table 1. Demographic, baseline, neuroradiological, and laboratory data for all ICH patients with an NLR higher or lower than 4.66

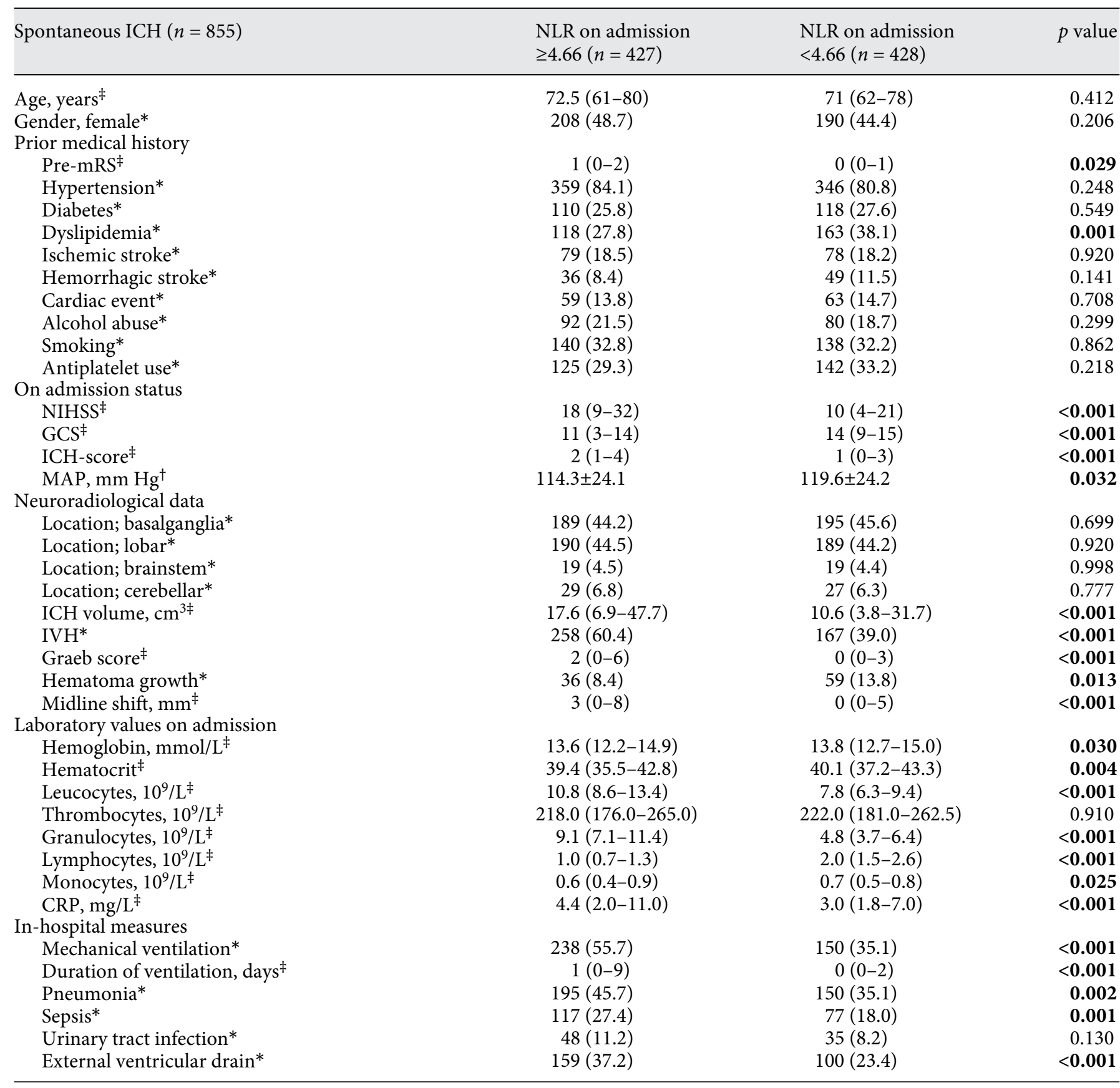

Values are ${ }^{*} n(\%),{ }^{\ddagger}$ median (interquartile range), or ${ }^{\dagger}$ mean $\pm \mathrm{SD}$. Bold values are significant.

ed with a better clinical status (NIHSS 12 [5-21] vs. 15 [6-28]; $p<0.005$ ), and imaging (hematoma volumes 10.6 [3.6-30.1] vs. $15.1[5.7-42.3] \mathrm{mL} ; p<0.004)$ showed less infectious complications (pneumonia: 76/214 [35.5\%] vs. 270/641 [42.1\%]; $p=0.088$ and sepsis: $35 / 214$ [16.4\%] vs. $162 / 641$ [25.3\%]; $p=0.007)$, required less mechanical ventilation $(73 / 214[34.1 \%]$ vs. $316 / 641[49.3 \%] ; p<$ $0.001)$ and external ventricular drain placement $(50 / 214$ [23.3\%] vs. $202 / 641$ [31.5\%]; $p=0.003$ ), as compared to patients with $N L R \geq 2.606$. Functional outcome was better in patients presenting with low NLR $(<2.606)$ compared to those with higher NLR (mRS 0-3: 82/214 [38.3\%] vs. 
Fig. 2. The distribution of the modified Rankin Scale (mRS; 3-month-outcome dichotomized into mRS 0-3 vs. 4-6) for patients with a median neutrophile-to-lymphocyte ratio (NLR) on admission $<4.66$ and $\geq 4.66$.

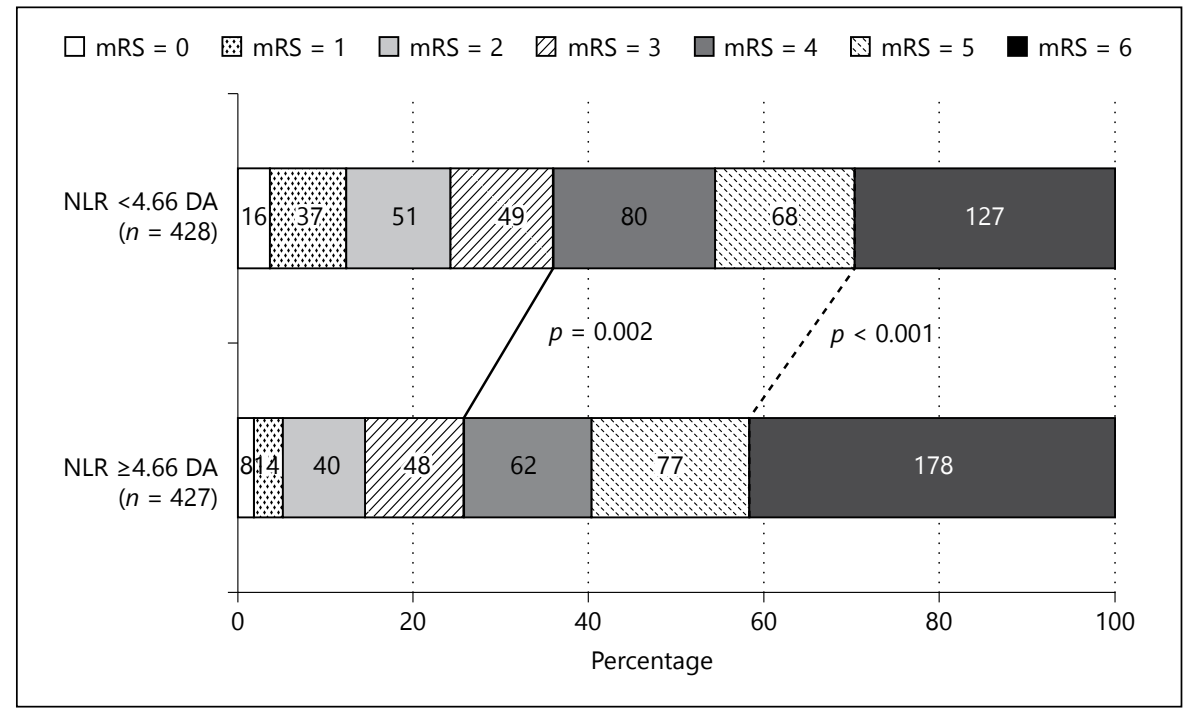

185/641 [28.9\%]; $p=0.009$ ). However, in-hospital mortality and mRS on discharge did not differ significantly among both groups (Table 2).

Of the 855 patients, 214 showed an NLR $\geq 8.508$ (Table 3). These patients had an impaired neurological status on admission (NIHSS $20.5[12-32]$ vs. 12 [523]; $p<0.001$; GCS 10 [3-13] vs. 13 [7-15]; $p<0.001)$ as well as increased hematoma volumes $(21.0$ [8.6-48.8] vs. 12.2 [4.1-34.9] $\mathrm{mL} ; p<0.001$; Table 3). Patients with NLR $\geq 8.508$ experienced significantly more often infectious complications (pneumonia 107/214 [50.0\%] vs. 240/641 [37.4\%]; $p=0.001$ and sepsis: $78 / 214[36.5 \%]$ vs. $116 / 641$ $[18.1 \%] ; p<0.001)$, required significantly more often mechanical ventilation and external ventricular drain (132/214 [61.7\%] vs. 258/641 [40.3\%]; and 88/214 [41.0\%] vs. $172 / 641$ [26.8\%]; both, $p<0.001)$. Both in-hospital mortality $(61 / 214$ [28.5\%] vs. $136 / 641[21.2 \%] ; p=0.041)$ and the proportion of patients with unfavorable functional outcome (mRS 4-6: 173/214 [80.8\%] vs. 418/641 [65.2\%]; $p<0.001)$ and 3-month mortality (95/214 [44.4\%] vs. 211/641 [33.0\%]; $p=0.002)$ were significantly higher in patients with NLR $\geq 8.508$ (Table 3 ).

\section{Discussion}

This study systematically investigated the natural course and clinical impact of NLR in a large cohort of ICH patients. As key findings, we observed increased baseline NLR levels compared to healthy individuals [26]. Further, an elevated NLR was linked to unfavorable baseline clinical and radiological parameters, increased infectious

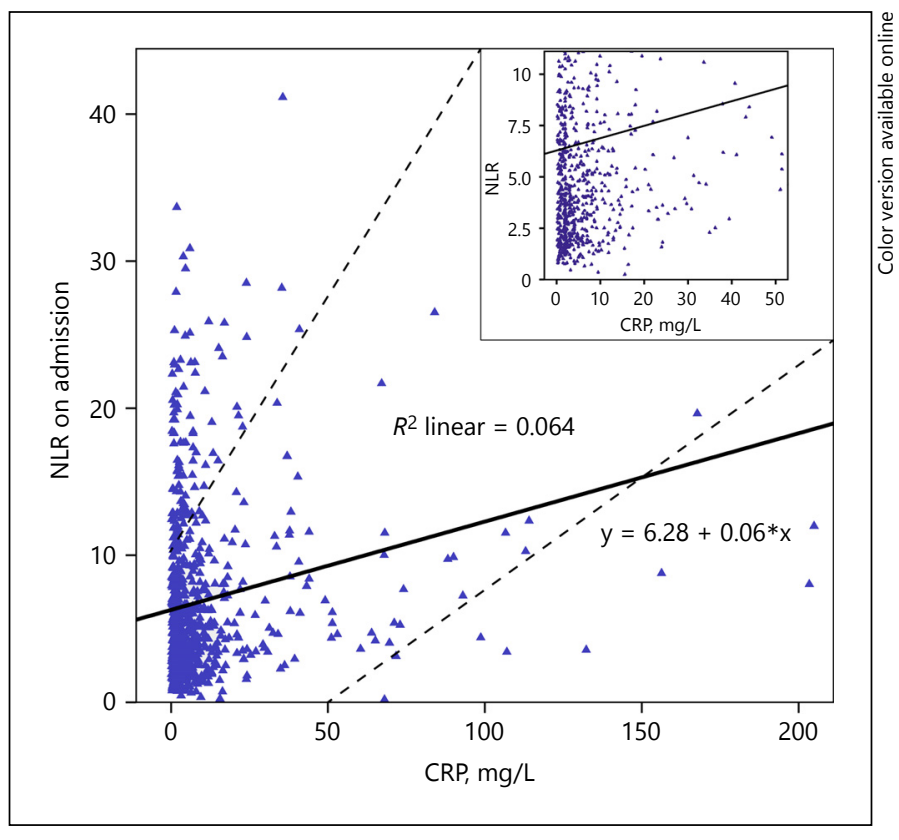

Fig. 3. Scatter plot of neutrophile-to-lymphocyte ratio and C-reactive protein (CRP; mg/L) on admission $\left(n=766, R^{2}=0.064 ; p<\right.$ 0.001).

complications, as well as elevated c-reactive-protein levels on admission translating into worse clinical endpoints, notably an independent association of NLROA with inhospital mortality.

Our results are in line with previous data indicating that an elevated NLR is associated with early neurological deterioration [32] as well as increased short-term mortality rates [16]. Consistent with recent publications, in- 
Table 2. Demographic, baseline, neuroradiological, and laboratory data for all ICH patients with an NLR lower or higher than 2.606

\begin{tabular}{|c|c|c|c|}
\hline Spontaneous ICH $(n=855)$ & $\begin{array}{l}\text { NLR on admission } \\
<2.606(n=214)\end{array}$ & $\begin{array}{l}\text { NLR on admission } \\
\geq 2.606(n=641)\end{array}$ & $p$ value \\
\hline Age, years ${ }^{\ddagger}$ & $71(63-78)$ & $72(61-79)$ & 0.584 \\
\hline \multicolumn{4}{|l|}{ Prior medical history } \\
\hline Pre-mRS $\ddagger$ & $0(0-1)$ & $1(0-2)$ & 0.002 \\
\hline Hypertension* & $170(79.4)$ & $530(82.7)$ & 0.286 \\
\hline Ischemic stroke* & $44(20.6)$ & $112(17.5)$ & 0.310 \\
\hline Hemorrhagic stroke* & $26(12.1)$ & $59(9.2)$ & 0.213 \\
\hline Cardiac event* & $38(17.8)$ & $84(13.1)$ & 0.092 \\
\hline Alcohol abuse* & $36(16.8)$ & $135(21.1)$ & 0.179 \\
\hline Smoking* & $75(35.1)$ & $200(31.2)$ & 0.296 \\
\hline ICH-score ${ }^{\ddagger}$ & $1(0-3)$ & $2(1-3)$ & 0.002 \\
\hline $\mathrm{MAP}, \mathrm{mm} \mathrm{Hg}^{\dagger}$ & $122.6 \pm 23.7$ & $114.9 \pm 24.4$ & 0.008 \\
\hline \multicolumn{4}{|l|}{ Neuroradiological data } \\
\hline Location; basalganglia* & $112(52.3)$ & $270(42.1)$ & 0.009 \\
\hline Location; lobar* & $77(36.0)$ & $300(46.8)$ & 0.006 \\
\hline Location; brainstem* & $13(6.1)$ & $26(4.1)$ & 0.221 \\
\hline Location; cerebellar* & $12(5.6)$ & $44(6.8)$ & 0.532 \\
\hline ICH volume, $\mathrm{cm}^{3 \ddagger}$ & $10.6(3.6-30.1)$ & $15.1(5.7-42.3)$ & 0.004 \\
\hline $\mathrm{IVH}^{*}$ & $89(41.6)$ & $336(52.4)$ & 0.006 \\
\hline Graeb score $e^{\ddagger}$ & $0(0-4)$ & $1(0-5)$ & 0.007 \\
\hline Hematoma growth* & $36(16.8)$ & $59(9.2)$ & 0.002 \\
\hline Midline shift, $\mathrm{mm}^{\ddagger}$ & $0(0-5)$ & $2(0-7)$ & 0.031 \\
\hline $\mathrm{CRP}, \mathrm{mg} / \mathrm{L}^{\ddagger}$ & $2.4(1.5-5.7)$ & $4.1(2.0-10.4)$ & $<0.001$ \\
\hline \multicolumn{4}{|l|}{ In-hospital measures } \\
\hline Mechanical ventilation* & $73(34.1)$ & $316(49.3)$ & $<0.001$ \\
\hline Duration of ventilation, days ${ }^{\ddagger}$ & $0(0-3)$ & $0(0-7)$ & 0.003 \\
\hline Pneumonia* & $76(35.5)$ & $270(42.1)$ & 0.088 \\
\hline Sepsis* & $35(16.4)$ & $162(25.3)$ & 0.007 \\
\hline Urinary tract infection* & $16(7.5)$ & $72(11.2)$ & 0.118 \\
\hline External ventricular drain* & $50(23.3)$ & $202(31.5)$ & 0.003 \\
\hline \multicolumn{4}{|l|}{ Outcome parameters } \\
\hline mRS discharge $\mathrm{f}^{\ddagger}$ & $5(3-6)$ & $5(3-5)$ & 0.950 \\
\hline mRS (3 months $)^{\ddagger}$ & $4(2-6)$ & $5(3-6)$ & 0.007 \\
\hline In-hospital mortality* & $46(21.5)$ & $154(24.0)$ & 0.450 \\
\hline Favorable outcome (mRS 0-3) 3 months* & $82(38.3)$ & $185(28.9)$ & 0.009 \\
\hline Non-favorable outcome (mRS 4-6) 3 months* & $132(61.6)$ & $456(71.1)$ & 0.009 \\
\hline 3-Month mortality* & $63(29.4)$ & $244(38.1)$ & 0.023 \\
\hline
\end{tabular}

Values are ${ }^{*} n(\%),{ }^{\ddagger}$ median (interquartile range), or ${ }^{\dagger}$ mean \pm SD. Bold values are significant, italic values show a statistical trend (i.e., $p<0.1)$. 
Table 3. Demographic, baseline, neuroradiological, and laboratory data for all ICH patients with an NLR higher or lower than 8.508

\begin{tabular}{|c|c|c|c|}
\hline Spontaneous ICH $(n=855)$ & $\begin{array}{l}\text { NLR on admission } \\
\geq 8.508(n=214)\end{array}$ & $\begin{array}{l}\text { NLR on admission } \\
<8.508(n=641)\end{array}$ & $p$ value \\
\hline Age, years ${ }^{\ddagger}$ & $73(61-80)$ & $71(62-79)$ & 0.516 \\
\hline \multicolumn{4}{|l|}{ Prior medical history } \\
\hline Pre-mRS $\ddagger$ & $1(0-3)$ & $0(0-2)$ & 0.012 \\
\hline Hypertension* & $187(87.4)$ & $513(80.0)$ & 0.016 \\
\hline Dyslipidemia* & $57(26.6)$ & $220(34.3)$ & 0.038 \\
\hline Ischemic stroke* & $41(19.2)$ & $117(18.3)$ & 0.764 \\
\hline Hemorrhagic stroke* & $21(9.8)$ & $64(10.0)$ & 0.920 \\
\hline Cardiac event* & $32(14.9)$ & $90(14.0)$ & 0.724 \\
\hline Alcohol abuse* & $56(26.2)$ & $117(18.3)$ & 0.013 \\
\hline Smoking* & $73(34.1)$ & $205(32.0)$ & 0.566 \\
\hline ICH-score ${ }^{\ddagger}$ & $3(1-4)$ & $2(1-3)$ & $<0.001$ \\
\hline $\mathrm{MAP}^{\dagger}$ & $114.2 \pm 26.9$ & $117.8 \pm 23.5$ & 0.258 \\
\hline \multicolumn{4}{|l|}{ Neuroradiological data } \\
\hline Location; basalganglia* & $93(43.5)$ & $290(45.2)$ & 0.646 \\
\hline Location; lobar* & $99(46.2)$ & $280(43.7)$ & 0.512 \\
\hline Location; brainstem* & $8(3.7)$ & $31(4.8)$ & 0.507 \\
\hline Location; cerebellar* & $14(6.5)$ & $43(6.7)$ & 0.920 \\
\hline ICH volume, $\mathrm{cm}^{3 \ddagger}$ & $21.0(8.6-48.8)$ & $12.2(4.1-34.9)$ & $<0.001$ \\
\hline $\mathrm{IVH}^{*}$ & $141(65.9)$ & $285(44.5)$ & $<0.001$ \\
\hline Graeb score $e^{\ddagger}$ & $3(0-6)$ & $0(0-4)$ & $<\mathbf{0 . 0 0 1}$ \\
\hline Hematoma growth* & $14(6.5)$ & $79(12.3)$ & 0.019 \\
\hline Monocytes, $10^{9} / \mathrm{L}^{\ddagger}$ & $0.61(0.43-0.94)$ & $0.65(0.49-0.83)$ & 0.650 \\
\hline $\mathrm{CRP}, \mathrm{mg} / \mathrm{L}^{\ddagger}$ & $4.7(2.0-15)$ & $3.3(1.8-8.0)$ & $<0.001$ \\
\hline \multicolumn{4}{|l|}{ In-hospital measures } \\
\hline Mechanical ventilation* & $132(61.7)$ & $258(40.3)$ & $<0.001$ \\
\hline Duration of ventilation, days ${ }^{\ddagger}$ & $1(0-12)$ & $0(0-3)$ & $<0.001$ \\
\hline Pneumonia* & $107(50.0)$ & $240(37.4)$ & 0.001 \\
\hline Sepsis* & $78(36.5)$ & $116(18.1)$ & $<0.001$ \\
\hline Urinary tract infection* & $24(11.2)$ & $60(9.4)$ & 0.431 \\
\hline External ventricular drain* & $88(41.0)$ & $172(26.8)$ & $<\mathbf{0 . 0 0 1}$ \\
\hline \multicolumn{4}{|l|}{ Outcome parameters } \\
\hline mRS discharge $\mathrm{f}^{\ddagger}$ & $5(4-6)$ & $4(3-5)$ & $<0.001$ \\
\hline mRS (3 months $)^{\ddagger}$ & $5(4-6)$ & $4(3-6)$ & $<0.001$ \\
\hline In-hospital mortality* & $61(28.5)$ & $136(21.2)$ & 0.041 \\
\hline Favorable outcome (mRS 0-3) 3 months* & $41(19.2)$ & $223(34.8)$ & $<0.001$ \\
\hline Non-favorable outcome (mRS 4-6) 3 months* & $173(80.8)$ & $418(65.2)$ & $<\mathbf{0 . 0 0 1}$ \\
\hline 3-Month mortality* & $95(44.4)$ & $211(33.0)$ & 0.002 \\
\hline
\end{tabular}

Values are ${ }^{*} n(\%),{ }^{\ddagger}$ median (interquartile range), or $^{\dagger}$ mean $\pm \mathrm{SD}$. Bold values are significant. 
flammation was significantly associated with unfavorable outcome [16, 33, 34]; however, we did not identify NLR as an independent predictor for outcome in ICH [6, $16]$, which is in line with data from INTERACT2 $[18,35]$. Regarding functional outcome and its possible relation to hematoma enlargement, Morotti et al. [19] - contrary to this study - found associations of higher neutrophil counts with reduced risk of hematoma expansion. The authors linked their finding to the hypothesis that the inflammatory response may exert beneficial aspects during the hyperacute phase such that activated neutrophils exhibit a procoagulant effect so that coagulation may be improved and therefore early hematoma expansion reduced [19].

However, there may also be an association of neutrophils, and NLR ratio respectively, with inflammatory complications [33, 36-38]. As demonstrated earlier, initial neutrophil infiltration contributes also to secondary brain injury [39]. The resulting expression of inflammatory markers, for example, interleukin-6 [12] and various pro-inflammatory cytokines $[11,12,36,38]$ may lead to further cellular DNA damage. Apoptosis and functional deactivation of peripheral lymphocytes $[34,40]$ reflect an important - though impaired - role in host defense. This can predispose to infectious complications later during hospital stay, as shown in our study. As NLR is known to be useful for the diagnosis of bacterial infections in patients with fever [41], we showed significant associations of CRP concentrations and a trend to independent associations with sepsis.

Given the complex inflammatory process, there are various limitations of our study. This study lacks a prospective and multi-center design without specific blood sampling analyses. Regimens for diagnosis as well as treatment of infections have not been reported why the significance of reported associations may be weakened.
Although NLR did not significantly change among our ICH cohort during hospital stay, varying time points between stroke-onset, occurrence of infections and blood sampling may represent important potential confounders. However, excluding patients with elevated CRP levels on admission $(>20 \mathrm{mg} / \mathrm{L}=$ twice the standard-level, and about $15 \%$ of our cohort) resulted in similar clinical endpoints (data not shown). Finally, we did not score for $\mathrm{ICH}$ etiologies, as there are probable associations between cerebral amyloid angiopathy and inflammation $[42,43]$. Further, outcome analyses were based on selfreporting rather than on objectively blinded assessment. Although we accounted for statistical bias, findings of this study may still overestimate causal and clinical associations.

In conclusion, our data reveal increased baseline NLR levels in $\mathrm{ICH}$, which is linked to unfavorable baseline parameters, increased infectious complications, and worse clinical endpoints. However, whether a close monitoring of specific subsets of ICH patients with increased NLR may result in beneficial outcome measures requires further investigations.

\section{Acknowledgments}

We thank Petra Burkardt for helping with data-acquisition.

\section{Sources of Funding}

The authors have no funding to declare.

\section{Disclosure Statement}

The authors have no conflicts of interest to declare.

\section{References}

1 Rueda-Clausen CF, Lopez-Jaramillo P, Luengas C, del Pilar Oubina M, Cachofeiro V, Lahera V: Inflammation but not endothelial dysfunction is associated with the severity of coronary artery disease in dyslipidemic subjects. Mediators Inflamm 2009; 2009:469169.

2 Libby P: What have we learned about the biology of atherosclerosis? The role of inflammation. Am J Cardiol 2001;88:3J-6J.

3 Balkwill F, Mantovani A: Inflammation and cancer: back to Virchow? Lancet 2001;357: 539-545.
4 Bhat $\mathrm{T}$, Teli S, Rijal J, Bhat $\mathrm{H}$, Raza M, Khoueiry G, Meghani M, Akhtar M, Costantino T: Neutrophil to lymphocyte ratio and cardiovascular diseases: a review. Expert Rev Cardiovasc Ther 2013;11: 55-59.

5 Wang F, Hu S, Ding Y, Ju X, Wang L, Lu Q, $\mathrm{Wu} \mathrm{X}$ : Neutrophil-to-lymphocyte ratio and 30-day mortality in patients with acute intracerebral hemorrhage. J Stroke Cerebrovasc Dis 2016;25:182-187.

6 Lattanzi S, Cagnetti C, Provinciali L, Silvestrini M: Neutrophil-to-lymphocyte ratio predicts the outcome of acute intracerebral hemorrhage. Stroke 2016;47:1654-1657.

7 Walsh KB, Sekar P, Langefeld CD, Moomaw CJ, Elkind MS, Boehme AK, James ML, Osborne J, Sheth KN, Woo D, Adeoye O: Monocyte count and 30-day case fatality in intracerebral hemorrhage. Stroke 2015;46:23022304.

8 Yang B, Wang S, Yu S, Chen Y, Li L, Zhang H, Zhao Y: Clq/tumor necrosis factor-related protein 3 inhibits oxidative stress during intracerebral hemorrhage via PKA signaling. Brain Res 2017;1657:176-184.
Neutrophil-to-Lymphocyte Ratio in Spontaneous ICH
Cerebrovasc Dis 2017;44:26-34 DOI: $10.1159 / 000468996$ 
9 Chen-Roetling J, Regan RF: Targeting the Nrf2-heme oxygenase-1 axis after intracerebral hemorrhage. Curr Pharm Des 2016, Epub ahead of print.

10 Tao X, Xie L, Duan C, Dai S, Ren J, Yan Y, Shen J, Lu H, Ge J: Up-regulation of interferon regulatory factor 3 involves in neuronal apoptosis after intracerebral hemorrhage in adult rats. Neurochem Res 2016;41:29372947.

11 Kantola T, Klintrup K, Vayrynen JP, Vornanen J, Bloigu R, Karhu T, Herzig KH, Napankangas J, Makela J, Karttunen TJ, Tuomisto A, Makinen MJ: Stage-dependent alterations of the serum cytokine pattern in colorectal carcinoma. Br J Cancer 2012;107: 1729-1736.

12 Tapia-Perez JH, Karagianis D, Zilke R, Koufuglou V, Bondar I, Schneider T: Assessment of systemic cellular inflammatory response after spontaneous intracerebral hemorrhage. Clin Neurol Neurosurg 2016;150:72-79.

13 Zahorec R: Ratio of neutrophil to lymphocyte counts - rapid and simple parameter of systemic inflammation and stress in critically ill. Bratisl Lek Listy 2001;102:5-14.

14 Gokhan S, Ozhasenekler A, Mansur Durgun H, Akil E, Ustundag M, Orak M: Neutrophil lymphocyte ratios in stroke subtypes and transient ischemic attack. Eur Rev Med Pharmacol Sci 2013;17:653-657.

15 Gibson PH, Cuthbertson BH, Croal BL, Rae D, El-Shafei H, Gibson G, Jeffrey RR, Buchan KG, Hillis GS: Usefulness of neutrophil/lymphocyte ratio as predictor of new-onset atrial fibrillation after coronary artery bypass grafting. Am J Cardiol 2010;105:186-191.

16 Tao C, Hu X, Wang J, Ma J, Li H, You C: Admission neutrophil count and neutrophil to lymphocyte ratio predict 90-day outcome in intracerebral hemorrhage. Biomark Med 2017;11:33-42.

17 Tao C, Wang J, Hu X, Ma J, Li H, You C: Clinical value of neutrophil to lymphocyte and platelet to lymphocyte ratio after aneurysmal subarachnoid hemorrhage. Neurocrit Care 2016, Epub ahead of print.

$18 \mathrm{Yu}$ S, Arima H, Heeley E, Delcourt C, Krause M, Peng B, Yang J, Wu G, Chen X, Chalmers J, Anderson CS: White blood cell count and clinical outcomes after intracerebral hemorrhage: the INTERACT2 trial. J Neurol Sci 2016;361:112-116.

19 Morotti A, Phuah CL, Anderson CD, Jessel MJ, Schwab K, Ayres AM, Pezzini A, Padovani A, Gurol ME, Viswanathan A, Greenberg SM, Goldstein JN, Rosand J: Leukocyte count and intracerebral hemorrhage expansion. Stroke 2016;47:1473-1478.

20 Kuramatsu JB, Gerner ST, Lucking H, Kloska SP, Schellinger PD, Kohrmann M, Huttner $\mathrm{HB}$ : Anemia is an independent prognostic factor in intracerebral hemorrhage: an observational cohort study. Crit Care 2013;17:R148.
21 Kuramatsu JB, Bobinger T, Volbers B, Staykov D, Lucking $\mathrm{H}$, Kloska SP, Kohrmann M, Huttner HB: Hyponatremia is an independent predictor of in-hospital mortality in spontaneous intracerebral hemorrhage. Stroke 2014;45:1285-1291.

22 Tejerina E, Esteban A, Fernandez-Segoviano P, Frutos-Vivar F, Aramburu J, Ballesteros D, Rodriguez-Barbero JM: Accuracy of clinical definitions of ventilator-associated pneumonia: comparison with autopsy findings. J Crit Care 2010;25:62-68.

23 Muckart DJ, Bhagwanjee S: American college of chest physicians/society of critical care medicine consensus conference definitions of the systemic inflammatory response syndrome and allied disorders in relation to critically injured patients. Crit Care Med 1997;25: 1789-1795.

24 Wilson ML, Gaido L: Laboratory diagnosis of urinary tract infections in adult patients. Clin Infect Dis 2004;38:1150-1158.

25 Wang X, Arima H, Al-Shahi Salman R, Woodward M, Heeley E, Stapf C, Lavados PM, Robinson T, Huang Y, Wang J, Delcourt C, Anderson CS: Rapid blood pressure lowering according to recovery at different time intervals after acute intracerebral hemorrhage: pooled analysis of the INTERACT studies. Cerebrovasc Dis 2015;39:242-248.

26 Azab B, Camacho-Rivera M, Taioli E: Average values and racial differences of neutrophil lymphocyte ratio among a nationally representative sample of United States subjects. PLoS One 2014;9:e112361.

27 Rankin J: Cerebral vascular accidents in patients over the age of 60 . I. General considerations. Scott Med J 1957;2:127-136.

28 Burgess RE, Warach S, Schaewe TJ, Copenhaver BR, Alger JR, Vespa P, Martin N, Saver JL, Kidwell CS: Development and validation of a simple conversion model for comparison of intracerebral hemorrhage volumes measured on CT and gradient recalled echo MRI. Stroke 2008;39:2017-2020.

29 Kothari RU, Brott T, Broderick JP, Barsan WG, Sauerbeck LR, Zuccarello M, Khoury J: The ABCs of measuring intracerebral hemorrhage volumes. Stroke 1996;27:1304-1305.

30 Brott T, Broderick J, Kothari R, Barsan W, Tomsick T, Sauerbeck L, Spilker J, Duldner J, Khoury J: Early hemorrhage growth in patients with intracerebral hemorrhage. Stroke 1997;28:1-5.

31 Graeb DA, Robertson WD, Lapointe JS, Nugent RA, Harrison PB: Computed tomographic diagnosis of intraventricular hemorrhage. Etiology and prognosis. Radiology 1982;143:91-96.

32 Leira R, Davalos A, Silva Y, Gil-Peralta A, Tejada J, Garcia M, Castillo J: Early neurologic deterioration in intracerebral hemorrhage: predictors and associated factors. Neurology 2004;63:461-467.
33 Hug A, Dalpke A, Wieczorek N, Giese T, Lorenz A, Auffarth G, Liesz A, Veltkamp R: Infarct volume is a major determiner of post-stroke immune cell function and susceptibility to infection. Stroke 2009;40: 3226-3232.

34 Liesz A, Ruger H, Purrucker J, Zorn M, Dalpke A, Mohlenbruch M, Englert S, Nawroth PP, Veltkamp R: Stress mediators and immune dysfunction in patients with acute cerebrovascular diseases. PLoS One 2013; 8:e74839.

35 Sato S, Arima H, Heeley E, Hirakawa Y, Delcourt C, Lindley RI, Robinson T, Huang Y, Morgenstern L, Stapf C, Wang J, Chalmers J, Anderson CS: Off-hour admission and outcomes in patients with acute intracerebral hemorrhage in the INTERACT2 trial. Cerebrovasc Dis 2015;40:114-120.

36 Motomura T, Shirabe K, Mano Y, Muto J, Toshima T, Umemoto Y, Fukuhara T, Uchiyama $H$, Ikegami T, Yoshizumi T, Soejima $Y$, Maehara Y: Neutrophil-lymphocyte ratio reflects hepatocellular carcinoma recurrence after liver transplantation via inflammatory microenvironment. J Hepatol 2013;58:5864.

37 Montecucco F, Liberale L, Bonaventura A, Vecchie A, Dallegri F, Carbone F: The role of inflammation in cardiovascular outcome. Curr Atheroscler Rep 2017;19:11.

38 Guthrie GJ, Charles KA, Roxburgh CS, Horgan PG, McMillan DC, Clarke SJ: The systemic inflammation-based neutrophil-lymphocyte ratio: experience in patients with cancer. Crit Rev Oncol Hematol 2013;88: 218-230.

39 Sansing LH, Harris TH, Kasner SE, Hunter CA, Kariko K: Neutrophil depletion diminishes monocyte infiltration and improves functional outcome after experimental intracerebral hemorrhage. Acta Neurochir Suppl 2011;111:173-178.

40 Meisel C, Schwab JM, Prass K, Meisel A, Dirnagl U: Central nervous system injury-induced immune deficiency syndrome. Nat Rev Neurosci 2005;6:775-786.

41 Naess A, Nilssen SS, Mo R, Eide GE, Sjursen $\mathrm{H}$ : Role of neutrophil to lymphocyte and monocyte to lymphocyte ratios in the diagnosis of bacterial infection in patients with fever. Infection 2016, Epub ahead of print.

42 Chu S, Xu F, Su Y, Chen H, Cheng X: Cerebral amyloid angiopathy (CAA)-related inflammation: comparison of inflammatory CAA and amyloid- $\beta$-related angiitis. J Alzheimers Dis 2016;51:525-532.

43 Salvarani C, Morris JM, Giannini C, Brown RD Jr, Christianson T, Hunder GG: Imaging findings of cerebral amyloid angiopathy, $A \beta$ related angiitis (ABRA), and cerebral amyloid angiopathy-related inflammation: a singleinstitution 25-year experience. Medicine (Baltimore) 2016;95:e3613. 